\title{
Reproducibility of the uptake of U(VI) onto degraded cement pastes and calcium silicate hydrate phases
}

\author{
By I. Pointeau ${ }^{1}$, C. Landesman ${ }^{2} *$, E. Giffaut ${ }^{3}$ and P. Reiller ${ }^{4}$ \\ ${ }^{1}$ L3MR, Laboratoire de Mesures et Modélisation de la Migration des Radionucléides, CEA Saclay, Direction de l'Energie Nucléaire, \\ Département de Physico-Chimie, Service d'Etude du Comportement des Radionucléides, Bâtiment 450, BP 11, \\ F-91191 Gif-sur-Yvette Cedex, France \\ ${ }^{2}$ Laboratoire SUBATECH, Groupe de Radiochimie, UMR 6457, Ecole des Mines de Nantes, CNRS, Université de Nantes, 4, rue A. Kastler, \\ La Chantrerie, BP 20722, F-44307 Cedex Nantes, France \\ 3 ANDRA, Agence Nationale pour la gestion des Déchets RAdioactifs, Parc de la Croix Blanche, 1/7, rue Jean-Monnet, \\ F-92298 Châtenay-Malabry Cedex, France \\ ${ }^{4}$ LSRM, Laboratoire de Spéciation des Radionucléides et des Molécules, CEA Saclay, Direction de l'Energie Nucléaire, \\ Département de Physico-Chimie, Service d'Etude du Comportement des Radionucléides, Bât. 391, BP 11, \\ F-91191 Gif-sur-Yvette Cedex, France
}

(Received September 26, 2003; accepted March 22, 2004)

\section{Cement / C-S-H / Degradation / Uranium / Sorption / Isotherm / Solubility}

Summary. The U(VI) uptake in degraded cement pastes was undertaken in the laboratories of CEA/L3MR and SUBATECH in order to check the reproducibility of the study. Two well hydrated cement pastes, CEM I (Ordinary Portland Cement, OPC) and CEM V (blast furnace slag (BFS) and fly ash added to OPC) were degraded using similar protocols. Equilibrium solutions and solid materials were characterised for three degradation states for each paste. All samples are free of portlandite and the $\mathrm{pH}$ of the equilibrated cement solutions vary in the range 9.8-12.2. Three calcium silicate hydrate phases $(\mathrm{C}-\mathrm{S}-\mathrm{H})$ were synthesised in order to compare the sorption properties of degraded cement pastes and of hydrate phases in similar $\mathrm{pH}$ conditions. In order to avoid precipitation processes, the operational solubility limit was evaluated before batch experiments. These solubility values vary significantly in the $\mathrm{pH}$ range [9-13] with a $2.4 \times 10^{-7} \mathrm{~mol} \mathrm{~L}^{-1}$ minimum at $\mathrm{pH}$ close to 10.5. In batch sorption experiments, the distribution ratio $R_{\mathrm{d}}$ values are high: $3 \times 10^{4}-1.5 \times 10^{5} \mathrm{~mL} \mathrm{~g}^{-1}$. The uptake of U(VI) increases when comparing the least and the most degraded cement pastes whereas the initial composition of cement has relatively insensitive effect. Sorption isotherms, expressed as a $\log \left[\mathrm{U}(\mathrm{VI})_{\text {solid }}\right] / \log \left[\mathrm{U}(\mathrm{VI})_{\text {solution }}\right]$ plots are linear. A slope of 1 is calculated indicating the predominance of sorption processes. As sorption and desorption values are close, the uptake mechanism seems reversible. The $R_{\mathrm{d}}$ values measured in C-S-H suspensions are in good agreement with $R_{\mathrm{d}}$ values of degraded cement pastes, and C-S-H materials could be one of the cementitious phases which control U(VI) uptake in cement pastes.

\section{Introduction}

In the French design of a deep radioactive waste repository, cement and concrete will be used as container or buffer

\footnotetext{
*Author for correspondence

(E-mail: catherine.landesman@subatech.in2p3.fr).
}

and backfill materials in the engineered barrier system. Indeed, cement and concrete not only have well-known mechanical and low permeability properties, but also have an important radionuclide ( $\mathrm{RN})$ immobilization potential. As cement and concrete are soluble materials, the surrounding water will be buffered at a high $\mathrm{pH}$ value (10-13), with high calcium and silicon concentrations. In these conditions, most of actinides and fission products will precipitate. Moreover, pastes present high specific surface areas (about $200 \mathrm{~m}^{2} \mathrm{~g}^{-1}$ [1]), which favors sorption of dissolved elements. Sorption mechanisms are difficult to elucidate, as cement composition is complex and evolves with ageing and degradation [2]. The literature review shows discrepancies in the distribution ratios $\left(R_{\mathrm{d}}\right)$ for $\mathrm{RN}$ in concrete systems. The term $R_{\mathrm{d}}$ relates to the quantity of RN sorbed to the equilibrium $\mathrm{RN}$ concentration in solution. The discrepancies may have different origins (type of cement, experimental protocol ...). Thus, there is a request from ANDRA in improving the knowledge of RN distribution coefficient $\left(R_{\mathrm{d}}\right)$ for specific type of cements, especially for degraded engineered barriers. An experimental study was performed in two laboratories CEA/L3MR and SUBATECH on RN uptake with cement degradation. From the numerous RN to be considered, only the study of U(VI) uptake was undertaken in both laboratories in order to check the reproducibility of the experimental results.

\section{Experimental}

\section{Cementitious materials preparation}

CEM I (Ordinary Portland Cement, OPC) and CEM V (blast furnace slag (BFS) and fly ash added to OPC), from Origny manufacturing, were used in this study. The clinker compositions are detailed in Table 1 . The cements were cured with a water/cement $(\mathrm{w} / \mathrm{c})$ ratio of 0.38 and kept for 4 years after setting in saturated limewater at $20^{\circ} \mathrm{C}$ to provide samples free from carbonation. Calculations per- 
Table 1. Initial chemical composition of the clinker and hydrated pastes (given in mass \%).

\begin{tabular}{lcccc}
\hline & \multicolumn{2}{c}{ CEM I } & \multicolumn{2}{c}{ CEM V } \\
\hline & Clinker $^{a}$ & Pastes $^{b}$ & Clinker $^{a}$ & Pastes $^{b}$ \\
\hline $\mathrm{SiO}_{2}$ & 20.6 & 16.53 & 29.17 & 22.9 \\
$\mathrm{Al}_{2} \mathrm{O}_{3}$ & 5.8 & 4.13 & 10.86 & 8.53 \\
$\mathrm{Fe}_{2} \mathrm{O}_{3}$ & 3.6 & 2.24 & 3.2 & 2.35 \\
$\mathrm{CaO}$ & 62.9 & 49.57 & 46.82 & 36.52 \\
$\mathrm{MgO}$ & 0.7 & 0.78 & 2.33 & 1.97 \\
$\mathrm{SO}_{3}$ & 3.1 & not measured & 2.66 & not measured \\
$\mathrm{Na}_{2} \mathrm{O}$ & 0.1 & 0.14 & 0.36 & 0.25 \\
$\mathrm{~K}_{2} \mathrm{O}$ & 0.9 & 0.39 & 1.37 & 1.18 \\
water & $/$ & $23.96^{c}$ & $/$ & $25.86^{c}$ \\
\hline
\end{tabular}

a: given by manufacturers;

b: ICP-MS analysis after $\mathrm{LiBO}_{2}$ fusion and dissolution with $\mathrm{HNO}_{3}$;

c: Water content as determined by calcinating at $1000^{\circ} \mathrm{C}, 1$ hour.

formed with PHREEQC [3] give $\mathrm{pH}=12.6$ and $[\mathrm{Ca}]=$ $2.25 \times 10^{-2} \mathrm{~mol} \mathrm{~L}^{-1}$ for this solution. The hydrated pastes were crushed and sieved in a glovebox under argon atmosphere and the 100-200 $\mu \mathrm{m}$ fraction was kept for the experiments.

Three degradation states were considered for each cement paste and test samples were prepared accordingly. The first two degradation states were obtained by mixing the cement powders with degassed deionized water (DDW: milliQ water (Millipore ${ }^{\circledR}$ ) bubbled with argon during 24 hours), see Table 2. Previous experiments showed that solid to water ratios $(\mathrm{S} / \mathrm{L})$ in the range of 0.03 to $12 \mathrm{~g} \mathrm{~L}^{-1}$ were relevant to obtain the two first degradation states free from portlandite $\left(\mathrm{Ca}(\mathrm{OH})_{2}\right)$ but still including calcium silicate hydrate phases, C-S-H $\left((0.7-1.7) \mathrm{CaO} \cdot \mathrm{SiO}_{2} \cdot y \mathrm{H}_{2} \mathrm{O}\right)$ and ettringite $\left(\left[\mathrm{Ca}_{3} \mathrm{Al}(\mathrm{OH})_{6} \cdot 12 \mathrm{H}_{2} \mathrm{O}\right]_{2}\left(\mathrm{SO}_{4}\right)_{3} \cdot 2 \mathrm{H}_{2} \mathrm{O}\right)$. All experiments and storages were carried out in HDPE bottles (high density polyethylene). The solid and liquid phases were filtered $\left(0.22 \mu \mathrm{m}\right.$ Millipore $\left.{ }^{\circledR}\right)$ after an aging period of 2 weeks. Applying a DDW hydrolysis leaching process to the synthesis of the third and most degraded state (free from ettringite) would mean that solids in a milligram scale have to be isolated from litre scale volumes which implies experimental difficulties. Thus, a more aggressive degradation protocol was used. The cement paste was first mixed with a $0.5 \mathrm{~mol} \mathrm{~L}^{-1} \mathrm{NH}_{4} \mathrm{NO}_{3}$ solution in order to accelerate the chemical degradation (see Table 2). Indeed, $\mathrm{NH}_{4} \mathrm{NO}_{3}$ solution allows quicker chemical dissolution of portlandite and a progressive decalcification of C-S-H. Similar chemical and mineralogical composition of the products gener- ated by both leaching processes are reported in [4], where experiments were done with higher $\mathrm{NH}_{4} \mathrm{NO}_{3}$ concentration. After the equilibration period, the cement suspensions were filtered $\left(0.22 \mu \mathrm{m}\right.$ Millipore $\left.{ }^{\circledR}\right)$, washed three times with $100 \mathrm{~mL}$ DDW and $\mathrm{pH}$ was checked. Then solids were mixed with DDW and shaken for at least 2 weeks.

Three C-S-H phases were synthesized for three $\mathrm{C} / \mathrm{S}$ ratio. $\mathrm{CaO}$ and silica fumed were mixed with DDW with $\mathrm{S} / \mathrm{W}$ ratios of $20 \mathrm{~g} \mathrm{~L}^{-1}$. After an aging period of 3 weeks, the suspensions were filtered through $0.22 \mu \mathrm{m}$ filters (Millipore $^{\circledR}$ ). The $\mathrm{C} / \mathrm{S}$ ratios were estimated from the difference between the initial amounts of $\mathrm{Ca}$ and $\mathrm{Si}$ and the measured concentrations of these elements in solutions.

All the solids were dried in desiccators, under argon atmosphere and with silica gel for 2 weeks. The filtered solutions (of cements and C-S-H) were stored in HDPE bottles upon argon atmosphere. Thus, the cementitious materials were dispersed in their equilibrium solutions in the sorption experiments.

$\mathrm{pH}$ was measured before filtration, with a microelectrode (Inlab, $\mathrm{KCl} 3 \mathrm{M}+\mathrm{AgCl}$ ) calibrated at $\mathrm{pH} 7.00$ and 12.42. The $\mathrm{pH}$ values were measured with an uncertainty of 0.05 . The solution compositions were analyzed at the CEA/L3MR laboratory by ion chromatography ( $\mathrm{Ca}, \mathrm{Na}$ and $\mathrm{K}$ ), capillary electrophoresis (sulphate), graphite atomic furnace absorption spectrometry (Al) and spectrophotometry $(\mathrm{Si})$. At SUBATECH laboratory, all ion concentrations were measured by inductively coupled plasma-mass spectroscopy (ICP-MS). Each sample was analysed three times and associated uncertainties are estimated to $15 \%$. The solid phases were characterized by X-ray diffraction (XRD), and the diffractogramms were compared to reference patterns from the JCPD database. The amount of water in the solids was estimated by loss on ignition analysis at $1000^{\circ} \mathrm{C}^{-1}$ hour.

The CEM I and CEM V cement pastes contained $4 \times 10^{-9} \mathrm{~mol} \mathrm{~g}^{-1}$ and $10^{-8} \mathrm{~mol} \mathrm{~g}^{-1}$ of ${ }^{238} \mathrm{U}$, respectively (ICP-MS analysis after $\mathrm{LiBO}_{2}$ fusion and dissolution with $\mathrm{HNO}_{3}$ ). However, no ${ }^{238} \mathrm{U}$ was detected in the degraded cement waters by ICP-MS (detection limit $10^{-10} \mathrm{~mol} \mathrm{~L}^{-1}$ ).

\section{Solubility of U(VI) in cement and C-S-H solutions and sorption isotherms of $\mathrm{U}(\mathrm{VI})$ on cement or $\mathrm{C}-\mathrm{S}-\mathrm{H}$ phases suspensions}

The solubility and sorption experiments were conducted in nitrogen-flushed gloveboxes. Batch solubility and sorption experiments were carried out in polysulfone or polypropylene copolymer centrifuge tubes. Indeed, these tubes have
Table 2. Chemical parameters and solid-solution aging time $(\mathrm{d}=$ day, $\mathrm{h}=$ hours $)$ for the synthesis of the degraded cement pastes.

\begin{tabular}{|c|c|c|c|c|c|}
\hline & & \multicolumn{2}{|c|}{ CEM I } & \multicolumn{2}{|c|}{ CEM V } \\
\hline & & SUBATECH & CEA/L3MR & SUBATECH & CEA/L3MR \\
\hline $1^{\text {st }}$ deg. state & DDW/CEM $\left(\mathrm{g} \mathrm{L}^{-1}\right)$ & $3.7 \quad(15 d)$ & $3.5 \quad(15 \mathrm{~d})$ & $12.5 \quad(15 \mathrm{~d})$ & $12.0 \quad(15 \mathrm{~d})$ \\
\hline $2^{\text {nd }}$ deg. state & DDW/CEM $\left(\mathrm{g} \mathrm{L}^{-1}\right)$ & $0.4 \quad(15 d)$ & $0.4 \quad(15 d)$ & $0.9 \quad(15 \mathrm{~d})$ & $0.8 \quad(15 d)$ \\
\hline $3^{\text {rd }}$ deg. state & $\begin{array}{l}\mathrm{CEM} \text { mass }(\mathrm{g}) \\
{\left[\mathrm{NH}_{4} \mathrm{NO}_{3}\right]\left(\mathrm{mol} \mathrm{L}^{-1}\right)} \\
\text { vol } \mathrm{NH}_{4} \mathrm{NO}_{3}(\mathrm{~L}) \\
\text { vol DDW }(\mathrm{L})\end{array}$ & $\begin{array}{l}1 \\
0.4 \\
0.03(0.5 \mathrm{~h}) \\
0.25(15 \mathrm{~d})\end{array}$ & $\begin{array}{c}4.8 \\
0.5 \\
0.61(10 \mathrm{~d}) \\
0.40(15 \mathrm{~d})\end{array}$ & $\begin{array}{l}1 \\
0.4 \\
0.03(0.5 \mathrm{~h}) \\
0.25(15 \mathrm{~d})\end{array}$ & $\begin{array}{c}4.8 \\
0.5 \\
0.38(10 \mathrm{~d}) \\
0.40(15 \mathrm{~d})\end{array}$ \\
\hline
\end{tabular}


good resistance to basic solutions and the measured sorption rate of $\mathrm{U}(\mathrm{VI})$ onto the walls was less than $2 \% .{ }^{232} \mathrm{U}\left(\mathrm{UO}_{2} \mathrm{Cl}_{2}\right.$ in $\mathrm{HCl} 2 \mathrm{M}$ ) is used as tracer. In order to avoid the interferences related to the formation of ${ }^{228} \mathrm{Th}$ and its daughters, the experimental time is limited to 3 weeks for U(VI) sorption experiments.

The operational solubility limit evaluation is not a rigorous solubility study because no attempt was undertaken to identify the solid phase(s) limiting the solubility of uranium in cement waters. The main goal of this study was to determine the highest amount of $\mathrm{U}(\mathrm{VI})$ which can be introduced in the batch without leading to a precipitation in the U(VI)cement suspensions. The solubility limit was determined by oversaturation experiments. A ${ }^{238} \mathrm{U}$ solution (dissolution of $\mathrm{UO}_{2}\left(\mathrm{NO}_{3}\right)_{2} \cdot 6 \mathrm{H}_{2} \mathrm{O}$ in $\mathrm{HNO}_{3} 10^{-1} \mathrm{~mol} \mathrm{~L} \mathrm{~L}^{-1}$ to prevent polynuclear formation $[5,6])$, was added to the cement solution, with a total $\mathrm{U}(\mathrm{VI})$ concentration in the experiments ranging of $8 \times 10^{-6}$ or $2 \times 10^{-4} \mathrm{~mol} \mathrm{~L}^{-1}$. Solubility of U(VI) was measured after 3 days of shaking. The solutions were centrifuged (50000 g for 1 hour) for analysis and $\mathrm{pH}$ was measured. Some experiments were made using subsequent filtration $\left(0.22 \mu \mathrm{m}\right.$ Millipore $\left.{ }^{\circledR}\right)$. The short shaking time (3 days) is compatible with the observation of Brownsword et al. [7] who showed through a kinetic study (1,20 and 33 days) that the measured solubilities did not change significantly with time.

Batch sorption experiments were carried out with a $\mathrm{S} / \mathrm{L}$ ratio in the range $1-2 \mathrm{~g} \mathrm{~L}^{-1}$. After equilibration by tridimensional agitation, the suspensions were precentrifuged at $8500 \mathrm{rpm}$ and subsequently filtered $\left(0.22 \mu \mathrm{m}\right.$ Millipore ${ }^{\circledR}$, Subatech) or centrifuged at $50000 \mathrm{~g}$ for 1 hour (CEA). The supernatants were analyzed by liquid scintillation counting in order to determine the residual amount of radioactive tracer.

Results are expressed as distribution ratio $R_{\mathrm{d}}$ values, which correspond to:

$$
\begin{aligned}
& R_{\mathrm{d}}\left(\mathrm{mL} \mathrm{g}^{-1}\right)=\frac{[\mathrm{U}]_{\text {sorbed }}\left(\mathrm{mol} \mathrm{g}^{-1}\right)}{[\mathrm{U}]_{\text {solution }}\left(\mathrm{mol} \mathrm{mL}^{-1}\right)} \\
& =\frac{[\mathrm{U}]_{\text {initial }}-[\mathrm{U}]_{\text {solution }}}{[\mathrm{U}]_{\text {solution }}} \times \frac{\text { solution volume }(\mathrm{mL})}{\text { mass per solid }(\mathrm{g})} .
\end{aligned}
$$

The mass of solid used for the $R_{\mathrm{d}}$ calculation is the dry mass determined by ignition at $1000{ }^{\circ} \mathrm{C}$.

The term "distribution coefficient $K_{\mathrm{d}}$ " is not used in this study. Determination of a $K_{\mathrm{d}}$ value requires three major conditions which are difficult to ensure in cementitious systems: i) the difference between initial and final $\left[{ }^{232} \mathrm{U}\right]$ in solution must be the result of sorption phenomena (whereas (co)precipitation may also occur in our cement systems); ii) $K_{\mathrm{d}}$ values have to be measured at equilibrium state and iii) the sorption equilibrium has to be reversible.

Desorption experiments were carried out in order to control the reversibility of the equilibrium. After centrifugation, the spiked solution was removed from the tube, and replaced by the same volume of equilibrated cement solution exempt from uranium.

The experimental uncertainties were measured by repeating 6 to 9 times the same batch experiment (same mass/volume ratio and same amount of ${ }^{232} \mathrm{U}$ ) for one cement system.

\section{Results and discussion}

\section{Cementitious materials and equilibrated waters characterizations}

For all cement waters [Ca], [Si] and $\mathrm{pH}$ were measured (see Fig. 1). The concentrations values $[\mathrm{Al}],[\mathrm{Na}],[\mathrm{K}]$ and $\left[\mathrm{SO}_{4}\right]$ are shown Table 3. The last column refers to the percentage of dried solid present in the synthesized degraded cement pastes. The $\mathrm{pH}$ is about 12.2 and [Ca] about $10^{-2} \mathrm{~mol} \mathrm{~L}^{-1}$, for the first degradation state, and 11.5 and $2 \times 10^{-3} \mathrm{~mol} \mathrm{~L}^{-1}$ for the second degradation state. The global $\mathrm{C} / \mathrm{S}$ ratio (calcium/silicium in the solids) ratio was estimated by assuming a linear relationship to be valid in a $[\mathrm{Ca}]$ concentration range of 2.2 to $22 \times 10^{-3} \mathrm{~mol} \mathrm{~L}^{-1}$ according to literature data [2]. The two first degradation states correspond then to $\mathrm{C} / \mathrm{S}$ equal to 1.3 and 1.0 respectively, and the concentration values for $\mathrm{Ca}$ and $\mathrm{Si}$ are close to those of synthesized $\mathrm{C}-\mathrm{S}-\mathrm{H}$ 1.3 and 1.0. For the most degraded cement phases, obtained after the ammonium nitrate leaching step, $\mathrm{pH}$ is about 9.9 and $\left[\mathrm{Ca}\right.$ ] about $8-9 \times 10^{-4} \mathrm{~mol} \mathrm{~L}^{-1}$. This value lies outside the indicated $[\mathrm{Ca}]$ range. A $\mathrm{C} / \mathrm{S}$ ratio could not be easily calculated and was estimated to $0.7( \pm 0.2)$ from SEM-EDX measurements (Scanning Electron Microscopy coupled with Energy Dispersive X-ray analysis).

The solubility data of C-S-H show that for CEM 1.3 and CEM 1.0, the concentrations of $\mathrm{Ca}$ and $\mathrm{Si}$ seem to be controlled by C-S-H phases (see Fig. 1). However, for CEM 0.7 ( $\mathrm{pH} 10), \mathrm{Ca}$ and $\mathrm{Si}$ concentrations are different from those of $\mathrm{C}-\mathrm{S}-\mathrm{H}$ 0.7. Thus, even if the $\mathrm{C} / \mathrm{S}$ ratio in the degraded cement and $\mathrm{C}-\mathrm{S}-\mathrm{H}$ phases are close to each other, one cannot exclude that another solid phase than $\mathrm{C}-\mathrm{S}-\mathrm{H}$ may control $\mathrm{Ca}$ and $\mathrm{Si}$ concentrations.

The cementitious pastes were characterized by XRD. Comparing the diffractograms of hydrated CEM I and CEM V cement pastes with JCPD reference patterns shows evidences for portlandite $\mathrm{Ca}(\mathrm{OH})_{2}$ (Ref. 04-0733), ettringite (Ref. 41-1451) and calcite $\mathrm{CaCO}_{3}$ (Ref. 05-0586).

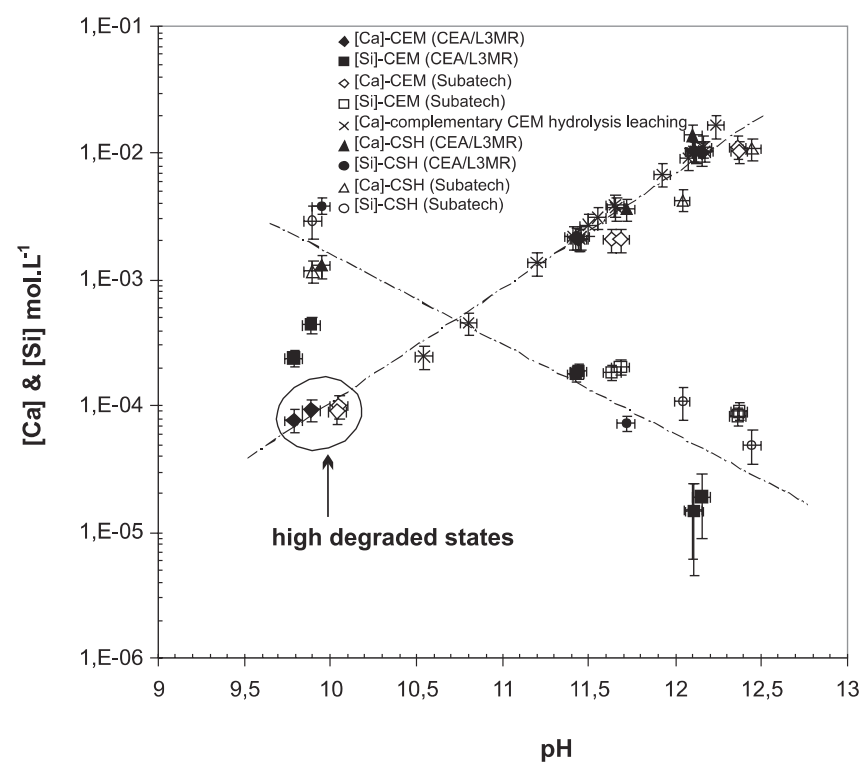

Fig. 1. Evolution of $\log [\mathrm{Ca}]$ and $\log [\mathrm{Si}]$ for CEM I and CEM V degraded cement pastes $v s$. pH. Values for the chemical composition of the C-S-H phases are also reported. The lines plotted in the graph indicate some general trends. 
Table 3. Chemical composition $\left(\mathrm{mol} \mathrm{L}^{-1}\right)$ of the solutions in contact with degraded cement and $\mathrm{C}-\mathrm{S}-\mathrm{H}$, and solid content $(\%)$ in cementitious materials determined by calcinating at $1000^{\circ} \mathrm{C}, 1$ hour (see text for uncertainties).

\begin{tabular}{|c|c|c|c|c|c|c|c|c|c|c|}
\hline & \multirow[b]{2}{*}{$\mathrm{C} / \mathrm{S}$ ratio } & \multicolumn{3}{|c|}{ CEM I } & \multicolumn{3}{|c|}{ CEM V } & \multicolumn{3}{|c|}{ C-S-H } \\
\hline & & 1.3 & 1.0 & 0.7 & 1.3 & 1.0 & 0.7 & 1.3 & 1.0 & 0.7 \\
\hline CEA/L3MR & $\begin{array}{l}\mathrm{pH} \\
{[\mathrm{Ca}]} \\
{[\mathrm{Si}]} \\
{[\mathrm{Al}]} \\
{\left[\mathrm{SO}_{4}{ }^{2-}\right]} \\
{[\mathrm{Na}]} \\
{[\mathrm{K}]} \\
\% \text { dried solid }\end{array}$ & $\begin{array}{c}12.17 \\
1.1 \times 10^{-2} \\
1.3 \times 10^{-5} \\
3.1 \times 10^{-5} \\
3.8 \times 10^{-5} \\
1.35 \times 10^{-4} \\
2.4 \times 10^{-4} \\
55.8 \pm 0.2\end{array}$ & $\begin{array}{l}11.46 \\
2.2 \times 10^{-3} \\
1.9 \times 10^{-4} \\
4.6 \times 10^{-4} \\
9.6 \times 10^{-5} \\
\text { < lim. det } \\
\text { < lim. det } \\
41.0 \pm 0.2\end{array}$ & $\begin{array}{l}\quad 9.89 \\
9.3 \times 10^{-5} \\
4.4 \times 10^{-4} \\
\text { not. meas. } \\
\text { not. meas. } \\
<\lim \text {. det } \\
<\lim . \text { det } \\
67.2 \pm 0.2\end{array}$ & $\begin{aligned} 12.18 \\
9.9 \times 10^{-3} \\
1.9 \times 10^{-5} \\
3.8 \times 10^{-5} \\
1.3 \times 10^{-5} \\
5.76 \times 10^{-4} \\
1.64 \times 10^{-3} \\
53.3 \pm 0.2\end{aligned}$ & $\begin{array}{c}11.45 \\
1.7 \times 10^{-3} \\
1.8 \times 10^{-4} \\
8.3 \times 10^{-5} \\
9.1 \times 10^{-5} \\
3.53 \times 10^{-5} \\
9.6 \times 10^{-5} \\
52.4 \pm 0.2\end{array}$ & $\begin{array}{l}\quad 9.79 \\
7.7 \times 10^{-5} \\
2.4 \times 10^{-4} \\
\text { not. meas. } \\
\text { not. meas. } \\
<\lim . \text { det } \\
<\lim . \text { det } \\
67.0 \pm 0.2\end{array}$ & $\begin{array}{c}12.10 \\
1.4 \times 10^{-2} \\
1.5 \times 10^{-5} \\
/ \\
/ \\
/ \\
/ \\
8.0 \pm 0.2\end{array}$ & $\begin{array}{c}11.72 \\
3.6 \times 10^{-3} \\
7.3 \times 10^{-5} \\
/ \\
/ \\
/ \\
7.5 \pm 0.2\end{array}$ & $\begin{array}{c}9.95 \\
1.3 \times 10^{-3} \\
3.9 \times 10^{-3} \\
/ \\
/ \\
/ \\
/ \\
5.7 \pm 0.2\end{array}$ \\
\hline SUBATECH & $\begin{array}{l}\mathrm{pH} \\
{[\mathrm{Ca}]} \\
{[\mathrm{Si}]} \\
{[\mathrm{Al}]} \\
{\left[\mathrm{SO}_{4}{ }^{2-}\right]} \\
{[\mathrm{Na}]} \\
{[\mathrm{K}]} \\
\% \text { dried solid }\end{array}$ & $\begin{array}{c}12.36 \\
1.1 \times 10^{-2} \\
8.3 \times 10^{-5} \\
2.6 \times 10^{-5} \\
3.5 \times 10^{-5} \\
2.02 \times 10^{-4} \\
1.35 \times 10^{-4} \\
82.3 \pm 0.2\end{array}$ & $\begin{array}{l}11.63 \\
2.1 \times 10^{-3} \\
1.9 \times 10^{-4} \\
3.8 \times 10^{-5} \\
5.1 \times 10^{-5} \\
5.6 \times 10^{-5} \\
<\lim . \text { det } \\
78.4 \pm 0.2\end{array}$ & $\begin{array}{l}10.05 \\
1.0 \times 10^{-4} \\
5.0 \times 10^{-4} \\
3 \times 10^{-6} \\
1.6 \times 10^{-5} \\
<\lim . \text { det } \\
<\lim . \operatorname{det} \\
79.6 \pm 0.2\end{array}$ & $\begin{aligned} 12.37 \\
1.0 \times 10^{-2} \\
9 \times 10^{-5} \\
8.2 \times 10^{-5} \\
1.4 \times 10^{-5} \\
2.62 \times 10^{-4} \\
1.09 \times 10^{-4} \\
80.1 \pm 0.2\end{aligned}$ & $\begin{array}{c}11.68 \\
2.1 \times 10^{-3} \\
1.9 \times 10^{-4} \\
7.9 \times 10^{-5} \\
6.5 \times 10^{-5} \\
9.0 \times 10^{-5} \\
6.1 \times 10^{-5} \\
75.8 \pm 0.2\end{array}$ & $\begin{array}{l}10.04 \\
9 \times 10^{-5} \\
2.7 \times 10^{-4} \\
1.0 \times 10^{-5} \\
1.4 \times 10^{-5} \\
\text { < lim. det } \\
\text { < lim. det } \\
81.2 \pm 0.2\end{array}$ & $\begin{array}{c}12.50 \\
1.1 \times 10^{-2} \\
4.9 \times 10^{-5} \\
/ \\
/ \\
/ \\
/ \\
10.8 \pm 0.2\end{array}$ & $\begin{array}{c}12.04 \\
4.3 \times 10^{-3} \\
1.1 \times 10^{-4} \\
/ \\
/ \\
/ \\
/ \\
11.9 \pm 0.2\end{array}$ & $\begin{array}{c}9.90 \\
1.2 \times 10^{-3} \\
2.9 \times 10^{-3} \\
/ \\
/ \\
/ \\
/ \\
14.1 \pm 0.2\end{array}$ \\
\hline
\end{tabular}

For the two first degraded CEM I and CEM V cement pastes $(\mathrm{C} / \mathrm{S} 1.3$ and 1.0$)$, portlandite was dissolved and there is evidence for C-S-H (Ref. 34-0002) and ettringite phases. Calcite is probably present (difficult discrimination between the closely located $\mathrm{CaCO}_{3}$ and $\mathrm{C}-\mathrm{S}-\mathrm{H}$ peaks) and there is evidence for calcium monocarboaluminate $\left(3 \mathrm{CaO} \cdot \mathrm{Al}_{2} \mathrm{O}_{3} \cdot \mathrm{CaCO}_{3} \cdot 11 \mathrm{H}_{2} \mathrm{O}\right)$ [8]. For the most degraded sample (C/S 0.7), no ettringite can be detected in XRD diffractogramms. A katoite/hydrogarnet phase $3 \mathrm{CaO} \cdot \mathrm{Al}_{2} \mathrm{O}_{3} \cdot \mathrm{SiO}_{2} \cdot 4 \mathrm{H}_{2} \mathrm{O}$ (Ref. 38-0368) and an alumino ferric phase $2 \mathrm{CaO} \cdot \mathrm{Al}_{1.38} \mathrm{Fe}_{0.62} \mathrm{O}_{3}$ (Ref. 42-1469) were detected, as monocarboaluminate and calcite. Identification of C-S-H was difficult as the intensities of peak are weak in these samples.

\section{Operational solubility limit evaluation}

The measured U(VI) concentrations are shown in Fig. 2. Within the range of experimental uncertainties, the data ob-

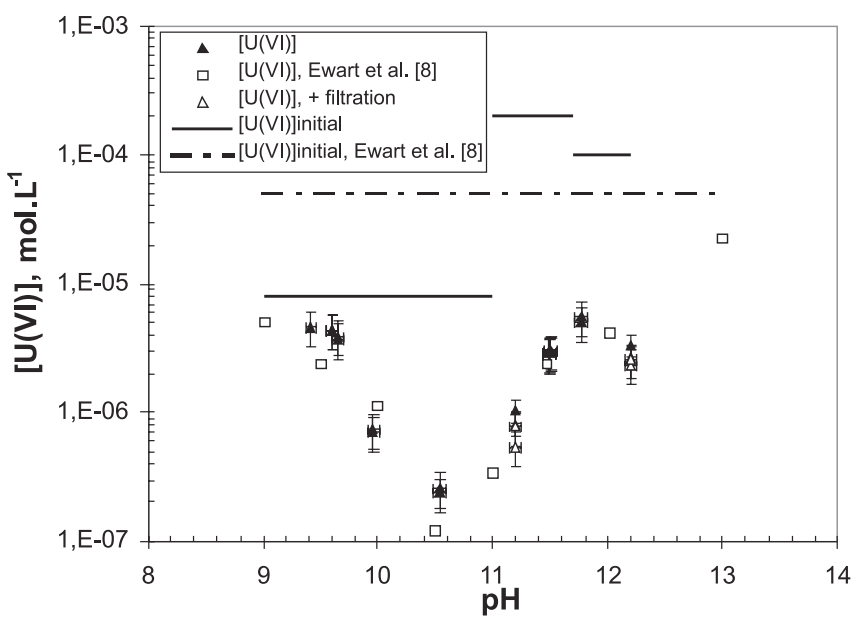

Fig. 2. Solubility limit evaluation for U(VI) in degraded cement waters. The data of this study are compared with the data taken from Ewart et al. [9]. The starting concentrations for $\mathrm{U}$ in the solution are specified as the horizontal lines. Open triangles designate data obtained after subsequent filtration (see text). tained by centrifugation alone are close to the data obtained by filtration after centrifugation $\left(0.22 \mu \mathrm{m}\right.$ Millipore $\left.{ }^{\circledR}\right)$. These results are in good agreement with U(VI) solubility data reported by Ewart et al. [9] which were obtained in a 9:1 Ordinary Portland Cement/Blast Furnace Slag cement water mixture $(\mathrm{pH} 12.2)$ where the $\mathrm{pH}$ has been adjusted with $\mathrm{HCl}$ and $\mathrm{NaOH}$. Ultra-filters in the range of 25 to $30 \mathrm{kD}(2-4 \mathrm{~nm})$ have been used. The $\mathrm{U}(\mathrm{VI})$ solubility varies significantly between $\mathrm{pH} 9$ to 13 showing a minimum at $\mathrm{pH}$ close to 10.5 and $[\mathrm{U}]=2.4 \times 10^{-7} \mathrm{~mol} \mathrm{~L}^{-1}$ compared to $1.2 \times 10^{-7} \mathrm{~mol} \mathrm{~L}^{-1}$ given by Ewart et al. [9]. In order to avoid $\mathrm{U}(\mathrm{VI})$ precipitation, batch sorption experiments have been carried out with an initial concentration of U(VI) less than $10^{-7} \mathrm{~mol} \mathrm{~L}^{-1}$.

\section{Batch sorption isotherms}

Initial $\mathrm{U}(\mathrm{VI})$ concentrations in batch sorption experiments were in the range of $2 \times 10^{-10} \mathrm{~mol} \mathrm{~L}^{-1}$ to $3.5 \times 10^{-9} \mathrm{~mol} \mathrm{~L}^{-1}$ in order to prevent precipitation of uranium solid phase(s). The uncertainties for the $R_{\mathrm{d}}$ values were measured for the CEM V 1.0 system and are estimated at $40 \%$. This value was applied for all systems.

\section{Kinetic study}

The $\mathrm{U}(\mathrm{VI})$ uptake was measured after 3, 9, and 21 days in the cement suspensions. No longer equilibration times were investigated. The experimental data showed that $R_{\mathrm{d}}$ values are very similar after 9 days and 21 days and the contact time of 9 days is required to reach a steady state. Nevertheless, the short time scale of our experiments does not allow to consider that a thermodynamic equilibrium ([U] $]_{\text {solution }} \leftrightarrow[\mathrm{U}]_{\text {solid }}$ ) is achieved. For this reason, our measured distribution coefficients are taken as $R_{\mathrm{d}}$-values, not $K_{\mathrm{d}}$-values.

\section{Evolution of $\boldsymbol{R}_{\mathrm{d}}$ with cement degradation}

The variation of $R_{\mathrm{d}}$ with $\mathrm{pH}$ is shown in Fig. 3. $\mathrm{pH}$ is one of the relevant parameters to characterize the degra- 


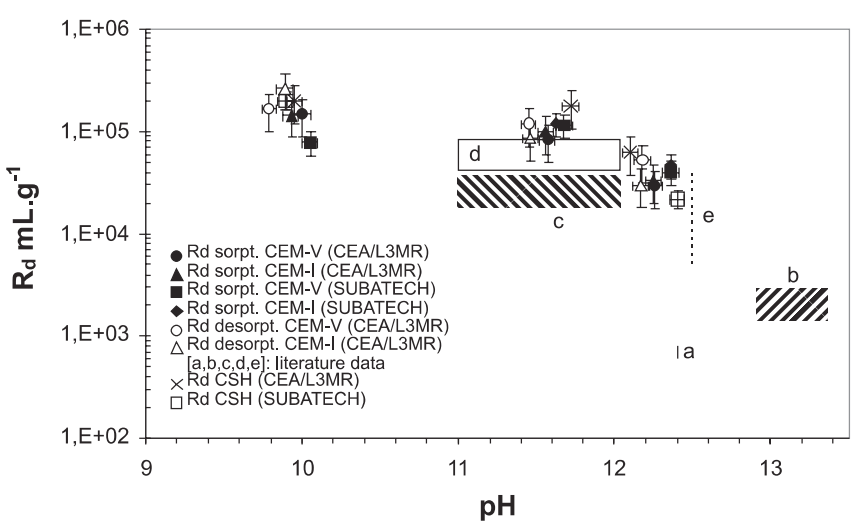

Fig. 3. U(VI) sorption after 14 days, and desorption after 6 days, in suspensions containing CEM I and CEM V degraded cement pastes and C-S-H phases. Literature data are: a - Aged Concrete [10]; b - Fresh concrete: OPC, BFS, fly ash ... [10]; c - Different types of cement: pure or blend of OPC/BFS/PFA [7]; $d$ - Hydrothermaly degraded cements [7]; e - Different types of concrete: OPC/lime/limestone aggregates [12].

dation state of the cement. The experimental results show i) there is an increase of $R_{\mathrm{d}}$ values when comparing the least and the most degraded cement pastes (globally $3 \times 10^{4}$ to $1.5 \times 10^{5} \mathrm{~mL} \mathrm{~g}^{-1}$ respectively). Moreover, it appears that there is not a great difference between the values obtained from the $2^{\text {nd }}$ and the $3^{\text {rd }}$ degradation state; ii) $R_{\mathrm{d}}$ values for CEM I and CEM V cement pastes are quite similar. It appears that for a given degradation state the initial composition of cement has no significant effect on the U(VI) uptake; iii) sorption and desorption $R_{\mathrm{d}}$ values are close to each other. Thus, the uptake mechanism seems to be reversible for each state of degradation in the time range of the study; iv) for a given $\mathrm{pH}, R_{\mathrm{d}}$ values measured in C-S-H suspensions are quite similar to those found for the cement pastes.

$R_{\mathrm{d}}$ values reported in the literature are lower than the $R_{\mathrm{d}}$ found in this study. Höglund et al. [10] have investigated the sorption of U(VI) on eight concrete types: two Portland systems, one cement aged for 70 years, and five other cements which are not described in detail. The sorption increased with time during the first weeks of contact and $R_{\mathrm{d}}$ values of $5 \times 10^{2}-10^{4} \mathrm{~mL} \mathrm{~g}^{-1}$ are reported. The lowest $R_{\mathrm{d}}$ values are reported for cement with a high alumina content, but no explanation is given for that result. Bradbury and Van Loon [11] reported values, taken from Bayliss et al. [12], between 5 and $40 \mathrm{~mL} \mathrm{~g}^{-1}$ at $\mathrm{pH} 12.5$. Higher $R_{\mathrm{d}}$ values were reported by Brownsword et al. [7] who have studied the sorption of U(VI) in cementitious repositories. The distribution coefficients found in this study after 35 days of contact were about $(2.5 \pm 1) \times 10^{4} \mathrm{~mL} \mathrm{~g}^{-1}$, irrespective of the cement type, the initial uranium concentration and filtration method. $R_{\mathrm{d}}$ values of $(6 \pm 2) \times 10^{4} \mathrm{~mL} \mathrm{~g}^{-1}$ were reached for degraded cements (hydrothermal treatment and leaching). These values are in agreement with the sorption data measured for high degraded cement pastes in the present work. Hence, the comparison of $R_{\mathrm{d}}$ values for U(VI) sorption to the degraded cement pastes and C-S-H phases, reflect the importance of these hydrate phases in controlling the distribution of $[\mathrm{U}]_{\text {solution }} \leftrightarrow[\mathrm{U}]_{\text {solid }}$ in cement suspensions.

Speciation calculations for U(VI) in cement solutions were undertaken using PHREEQC. Data for complexation constants are those taken from the NEA database [5]. At an initial $\mathrm{U}(\mathrm{VI})$ concentration of $10^{-9} \mathrm{~mol} \mathrm{~L}^{-1}, \mathrm{UO}_{2}(\mathrm{OH})_{3}{ }^{-}$is the major species (around 95\%) in the $\mathrm{pH}$ range 10-12.2. $\mathrm{UO}_{2}(\mathrm{OH})_{2}(\mathrm{aq})$ and $\mathrm{UO}_{2}(\mathrm{OH})_{4}{ }^{2-}$ are the other species. Zeta potential measurements on $\mathrm{C}-\mathrm{S}-\mathrm{H}$ phases $[13,14]$ gave positive surface charge values for $\mathrm{C} / \mathrm{S} \geq 1(\mathrm{pH} \geq 11.5$ in this work) and negative charge for phases with $\mathrm{C} / \mathrm{S} \leq 1$ ( $\mathrm{pH} \leq$ 11.5 in this work). This charge reversal is attributed to the sorption of $\mathrm{Ca}^{2+}$ on silanol sites through the surface complexation equilibrium:

$$
>\mathrm{SiOH}+\mathrm{Ca}^{2+} \rightleftarrows>\mathrm{SiOCa}^{+}+\mathrm{H}^{+}
$$

These observations suggest that anionic U(VI) hydroxide species are repelled from the negative surface when $\mathrm{pH}$ decreases. A reverse trend is observed with degraded cement pastes ( $R_{\mathrm{d}}$-values increase when $\mathrm{pH}$ decreases). Nevertheless, the trends are in agreement with those observed for $\mathrm{Pb}$ (II) sorption on $\mathrm{C}-\mathrm{S}-\mathrm{H}$ phases [15], where the author proposes the surface complex formation of $\mathrm{Pb}(\mathrm{OH})_{2}(\mathrm{aq})$ and $\mathrm{Pb}(\mathrm{OH})_{3}{ }^{-}$with $>\mathrm{SiOH}$ and $>\mathrm{SiOCa}^{+}$surface sites. A similar mechanism could be considered in the case of uranium(VI).

\section{Sorption isotherms}

Sorption isotherms were carried out on CEM 1.3, CEM 1.0, CEM 0.7, C-S-H 1.3 and C-S-H 0.7 systems. $\log [\mathrm{U}]_{\text {sorbed }}$ values are reported in Fig. 4 ([U] given in $\mathrm{mol} \mathrm{g}^{-1}$ ) as a function of $\log [\mathrm{U}]_{\text {solution }}\left(\mathrm{mol} \mathrm{L}^{-1}\right)$. Linear isotherm slopes of $0.83 \pm 0.13,0.98 \pm 0.08,0.85 \pm 0.33,1.01 \pm 0.03$ and $1.04 \pm 0.05$, respectively, are calculated for each system. A slope of 1 reflects ideal sorption behaviour [16]. The regression was made by least-squares analysis and the uncertainties were calculated with the Student coefficient $(95 \%$ confidence interval). The sorption isotherms obtained for all different cementitious systems are presented in the same $\log [\mathrm{U}]_{\text {sorbed }}-\log [\mathrm{U}]_{\text {solution }}$ plot. Only the linear part of each isotherm is displayed. However, the isotherms cannot be compared directly, as each system has a different solution composition and different solid composition. For CEM 1.0 and CEM 0.7 the isotherm slopes decrease for U(VI) concentrations beyond $10^{-9} \mathrm{~mol} \mathrm{~L}^{-1}$ which may be the result

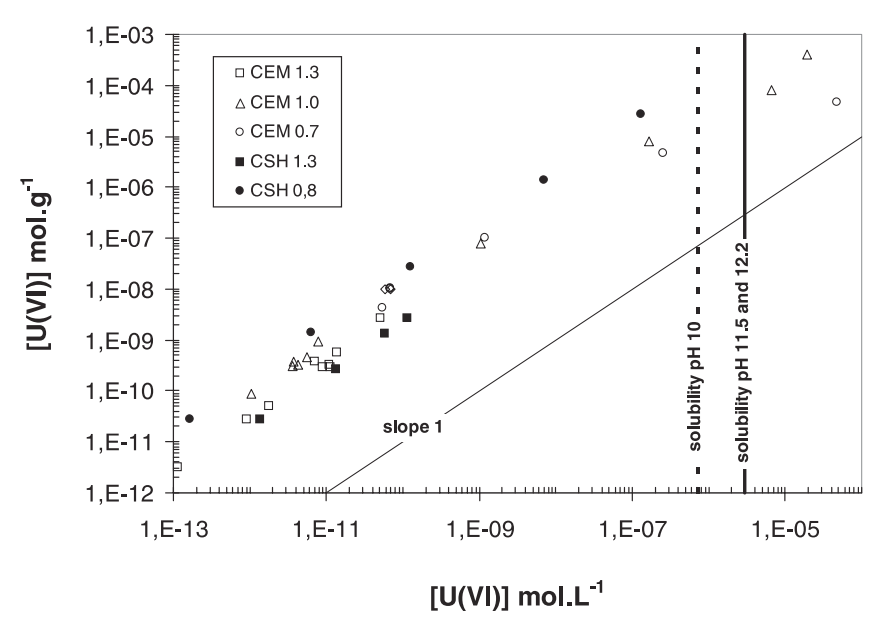

Fig. 4. Isotherms for the sorption of U(VI) on degraded CEM I and CEM V cement pastes and C-S-H phases. Uncertainties are not specified in the graph as the figure will then become unreadable. 
of saturation of sorption sites. The concentration of sorbed $\mathrm{U}(\mathrm{VI})$ is about $7-8 \times 10^{-8} \mathrm{molg}^{-1}$ at a concentration of $\mathrm{U}(\mathrm{VI})$ in solution of $10^{-9} \mathrm{~mol} \mathrm{~L}^{-1}$.

The ${ }^{238} \mathrm{U}$ amount initially present in the cement could undergo an isotopic exchange reaction with ${ }^{232} \mathrm{U}$, which could also contribute to the ${ }^{232} \mathrm{U}$ uptake. Initial ${ }^{238} \mathrm{U}$ amounts of $4 \times 10^{-9} \mathrm{~mol} \mathrm{~g}^{-1}$ and $10^{-8} \mathrm{~mol} \mathrm{~g}^{-1}$ were measured in hydrated CEM I and CEM V, respectively. Thus, even if all the ${ }^{238} \mathrm{U}$ was available for isotopic exchange, the concentration is lower than the lowest surface site concentration derived from isotherms. Moreover, the U(VI) uptake in C-S-H suspensions was similar, even though no initial ${ }^{238} \mathrm{U}$ content was measured in $\mathrm{C}-\mathrm{S}-\mathrm{H}$. Thus, isotopic exchange cannot solely explain the U(VI) uptake by the degraded cement pastes. The identification of the sorption mechanism still needs further experimental efforts. Spectroscopic studies are difficult to perform, as the concentration of uranium must be high enough to carry out measurements. For example, Sylwester et al. [17] tried to improve the knowledge of the sorption mechanism of uranium(VI) on untreated and hydrothermally treated cements at different $\mathrm{pH}$ by EXAFS. Results are consistent with surface adsorption and/or precipitation ( $\mathrm{U}-\mathrm{U}$ interactions were also observed). In future work, spectroscopic studies are envisaged and the samples will be synthesized with U(VI) concentrations below the solubility limit.

\section{Conclusion}

This study is an attempt to check the reproducibility of U(VI) sorption on degraded cement pastes. The results obtained by two laboratories agree well and allow to ascertain the $R_{\mathrm{d}}$ values for this element. Preliminary operational solubility experiments were used to define the experimental condition that way that precipitation is avoided. The $\mathrm{pH}$ values in solutions equilibrated with degraded cement pastes vary in the range 9.8 to 12.2 , and $R_{\mathrm{d}}$ values for $\mathrm{U}(\mathrm{VI})$ sorption weakly increase from $3 \times 10^{4}$ to $1-1.5 \times 10^{5} \mathrm{~mL} \mathrm{~g}^{-1}$ and do not depend on the initial type of cement paste. The uptake is reversible and sorption is identified as ideal as suggested by a slope of 1 of the isotherm log-log plot. The uptake of $\mathrm{U}(\mathrm{VI})$ in cement suspensions seems to be controlled by the $\mathrm{C}-\mathrm{S}-\mathrm{H}$ phases. The saturation of the cement sites was ob- served for U(VI) concentrations above $10^{-9} \mathrm{~mol} \mathrm{~L}^{-1}$ but the uptake mechanism is not yet identified (isotopic exchange, surface complexation ...).

Acknowledgment. This study has been financially supported by ANDRA. The authors would like to thank Dr. Jacques Ly, Dr. Cyrille Alliot, Dr. Hughes Peycelon and Patrick Le Bescop for useful conversations, Nathalie Coreau (CEA) and Céline Moisan (Subatech) for their work in the experimental part, and the LECBA laboratory for the hydrated cement pastes. The authors also thank two anonymous reviewers for examining the manuscript and for their constructive remarks.

\section{References}

1. Taylor, H. F. W.: Cement chemistry. $2^{\text {nd }}$ edn., Thomas Telford Publishing, London (2003) p. 235.

2. Berner, U. R.: Radiochim. Acta 44/45, 387 (1988).

3. Parkhurst, D. L., Appelo, C. A. J.: User's guide to PHREEQC (version 2) - a computer program for speciation, batch-reaction, one-dimensional transport, and inverse geochemical calculations. U.S. Geological Survey, Water-Resources Investigations, Report 99-4259, Lakewood, Colorado, USA (1999).

4. Carde, C.: Thesis. Université de Toulouse INSA (1996).

5. Kragten, J.: Atlas of metal-ligand equilibria in aqueous solution. Ellis Horwood Ltd., London (1978) p. 689.

6. Grenthe, I., Fuger, L., Konings, R. G. M., Lemire, R. J., Muller, A. B., Nguyen-Trung, C., Wanner, H.: Chemical thermodynamics of uranium. North Holland (1992).

7. Brownsword, M., Buchan, A. B., Ewart, F. T., McCrohon, R., Ormerod, G. J., Smith-Briggs, J. L., Thomason, H. P.: Mater. Res. Soc. Symp. Proc. 176, 577 (1990).

8. Pöllman, H.: Thesis. Nürnberg University (1990).

9. Ewart, F. T., Smith-Briggs, J. L., Thomason, H. P., Williams, S. J. Waste Management 12, 241 (1992).

10. Höglund, S., Eliasson, L., Allard, B., Andersson, K. Torstenfelt, B.: Mater. Res. Soc. Symp. Proc. 50, 683 (1985)

11. Bradbury, M., Van Loon, L.: PSI report 98-01 (1998).

12. Bayliss, S., McCrohon, R., Moreton, A., Oliver, P., Pilkington, N., Thomason, H. P.: BNES Conference, Manchester 11\&12 Jan. (1996).

13. Nachbaur, L., Nkinamubanzi, P.-C., Nonat, A., Mutin, J.-C.: J. Colloid Interf. Sci. 202, 261 (1998).

14. Viallis-Terrisse, H., Nonat, A., Petit, J.-C.: J. Colloid Interf. Sci. 244, 58 (2001).

15. Pointeau, I.: Thesis. Université de Champagne-Ardenne, Reims (2000).

16. Stumm, W., Morgan, J. J.: Aquatic Chemistry, chemical equilibria and rates in natural waters. $3^{\text {rd }}$ edn., Wiley, New York (1996) p. 521 .

17. Sylwester, E. R., Allen, P. G., Zhao, P., Viani, B. E.: Mater. Res. Soc. Symp. Proc. 608, 307 (2000). 